\title{
Mechanisms for the Ultrasonic Enhancement of Dairy Whey Ultrafiltration
}

by

S. Muthukumaran ${ }^{1}$, S.E. Kentish ${ }^{1}$, M. Ashokkumar ${ }^{2}$, G.W. Stevens ${ }^{1}$

Particulate Fluids Processing Centre, ${ }^{1}$ Department of Chemical and Biomolecular Engineering, ${ }^{2}$ School of Chemistry, University of Melbourne, Victoria 3010 Australia

Corresponding Author: S.E. Kentish, sandraek@unimelb.edu.au,

Tel: +61 38344 6682, Fax: +61 383444153 


\begin{abstract}
Low frequency ultrasound has been used to facilitate cross flow ultrafiltration of dairy whey solutions. Experimental results show that ultrasonic irradiation at low power levels can significantly enhance the permeate flux with an enhancement factor of between 1.2 and 1.7. The use of turbulence promoters (spacers) in combination with ultrasound can lead to a doubling in the permeate flux. The application of a combined pore blockage/cake resistance model to the observed experimental data suggests that the use of ultrasound acts to lower the compressibility of both the initial protein deposit and the growing cake. Conversely, the pore blockage parameter is not significantly affected. The use of a gel concentration polarization model shows that the ultrasonic irradiation increases the mass transfer coefficient within the concentration polarisation layer. Electron microscopy results showed no evidence that the ultrasonic irradiation altered the membrane integrity. HPLC analysis of the whey proteins in the feed solution before and after sonication showed that the concentration profile of the whey proteins was also not affected by the sonication process.
\end{abstract}

Keywords: Fouling: ultrasound; spacers; modelling; whey proteins; ultrafiltration 


\section{Introduction}

Ultrafiltration is a pressure-driven membrane process widely used in the dairy industry for whey protein concentration. One of the critical issues in the performance of such ultrafiltration processes is the decline in permeate flux that occurs as a result of both concentration polarization and membrane fouling. Concentration polarization occurs when a concentration gradient of the retained components is formed on or near the membrane surface. This phenomenon is predominantly a function of membrane hydrodynamics. Conversely, fouling is the largely irreversible deposition of material on the membrane surface or within its pores.

Various methods have been used to reduce the negative effects of concentration polarization and fouling. Techniques shown to be effective include turbulence promoters $[1,2]$, pulsatile flow [3, 4], vortex mixing [5], unsteady jet [6], gas sparged membrane filtration [7] and two phase gas liquid flow $[8,9]$. There is also currently much interest in the prevention of membrane fouling by methods termed as 'assisted filtration'. Here, electrical and sonic forces are used to modify the filtration performance.

Muralidhara and Tarleton [10-12] have shown that both electric and ultrasonic fields can reduce membrane fouling and in turn enhance flux. They observed a synergistic effect when both the fields were applied simultaneously. Recently, a number of other researchers have also demonstrated the effective use of ultrasound (US) alone to enhance the permeate flux [13-29]. Our own previous results have shown that ultrasound can assist during membrane cleaning to restore initial permeate fluxes $[30,31]$. This work has led to a general conclusion that ultrasound is very effective in enhancing filtration under a range of operating conditions and that ultrasound does not damage the membrane surface or increase the pore size of the membranes [14, 19, 21, 29]. However, very few workers have 
considered the mechanism by which the ultrasound affects flux improvement, or have attempted to model such effects [32].

There are four specific effects of ultrasonic irradiation, which could be harnessed to improve the filtration processes. Firstly, sonication can cause agglomeration of fine particles, thus potentially reducing pore blockage and cake compaction. Secondly, sonication can supply sufficient mechanical vibrational energy to the system to keep particles partly suspended and therefore leave more free channels for solvent elution. Thirdly, cavitating bubbles can scour surfaces and can reach the crevices that are not easily reached by conventional cleaning methods. Finally, acoustic streaming causes turbulence which result in bulk water movement toward and away from the membrane cake layer, with velocity gradients near the cake layer that may again score particles from the surface.

In the present study, low frequency ultrasound has been used to facilitate the cross flow ultrafiltration of a dairy whey solution. A range of models are available to predict the flux rate through ultrafiltration membranes [33-35]. In this study flux decay curves have been analyzed using the model developed by Ho and Zydney [34] for protein microfiltration. This model accounts for both pore blockage and cake formation simultaneously. Ho and Zydney assume that the initial flux decline is due to the physical deposition of large aggregates across the pore mouths. Their pore blockage parameter, $\alpha$, is equal to the membrane area blocked per unit mass of protein convected to the membrane surface, and thus is fundamentally an indication of the protein aggregate size.

Unlike complete pore blocking models, these aggregates are presumed to allow some fluid flow through the blocked pores. The flux through these blocked pores, $J_{\text {blocked }}$ is:

$$
J_{\text {blocked }}=\frac{\Delta \mathrm{P}}{\mu\left(R_{m}+R_{p}\right)}
$$


where $\Delta \mathrm{P}$ is the transmembrane pressure (TMP), $\mu$ is the solution viscosity, $R_{m}$ is the clean membrane resistance and $R_{p}$ is the resistance of the protein deposit that forms over the blocked surface. Over time the resistance to flow through the blocked pores increases due to the growth of the cake layer. This change in resistance is expressed as:

$\frac{d R_{p}}{d t}=f^{\prime} R^{\prime} J_{\text {blocked }} C_{b}$

where the group $f^{\prime} R^{\prime}$ represents the rate of increase of the protein layer resistance with time and $C_{b}$ is the bulk protein concentration.

In their initial model development, Ho and Zydney considered a spatial variation in cake thickness over the surface of the membrane. However a simplified model using a uniform cake resistance was shown to provide nearly similar results. On integration,

$R_{p}=\left(R_{m}+R_{p o}\right) \sqrt{1+\frac{2 f^{\prime} R^{\prime} \Delta \mathrm{P} C_{b} t}{\mu\left(R_{m}+R_{p o}\right)^{2}}}-R_{m}$

where $R_{p o}$ is the initial resistance of the protein deposit. The filtrate flux through the fouled membrane is then equal to the sum of the flow rate through open and blocked pores.

$$
\frac{J}{J_{0}}=\exp \left(-\frac{\alpha \Delta \mathrm{P} C_{b}}{\mu R_{m}} t\right)+\frac{R_{m}}{R_{m}+R_{p}}\left[1-\exp \left(\frac{\alpha \Delta \mathrm{P} C_{b}}{\mu R_{m}} t\right)\right]
$$

In this manner, the permeate flowrate can be completely characterized by three parameters, the pore blockage parameter $(\alpha)$, the initial resistance of the protein deposit $\left(R_{p o}\right)$ and the cake growth factor $\left(f^{\prime} R^{\prime}\right)$. 
Conversely, the gel polarization model assumes that a concentration polarized boundary layer exists above the precipitated cake or gel layer and is classically modeled using the following equation [33, 36].

$J_{v}\left(c-c_{p}\right)=-D\left(\frac{d c}{d x}\right)$

where $\mathrm{c}$ is the protein concentration within the concentration polarization layer and $c_{p}$ that of the permeate. $\mathrm{D}$ is the diffusion coefficient of the protein molecules. Integrating this equation across the concentration polarization layer, the permeate flux can be given by

$$
J_{v}=k \ln \left[\frac{\left(c_{G}-c_{p}\right)}{\left(c_{f}-c_{p}\right)}\right],
$$

where $\mathrm{k}$ is the mass transfer coefficient, $k=D / \delta$, with $\delta$ the thickness of the concentration polarization layer. $c_{G}$ is the protein concentration at the boundary with the gel layer of precipitated solids, and $c_{f}$ is the bulk feed concentration. In the case of high solute rejection, $c_{p} \rightarrow 0$ and the above equation becomes

$$
J_{v}=k \ln \left(c_{G} / c_{f}\right),
$$

or

$$
J_{v}=k \ln \left(c_{G}\right)-k \ln \left(c_{f}\right)
$$


The rejection of an ultrafiltration membrane for protein molecules is generally very high, especially when a gel layer is formed on the membrane surface. Hence the above equation is ordinarily used for the analysis of ultrafiltration fluxes.

\section{Materials and methods}

\section{Experimental Setup}

The experimental set up, similar to that described elsewhere [30], is shown in Figure 1. Flat sheet polysulfone ultrafiltration membranes with 30,000 MWCO and an effective membrane area of $30 \mathrm{~cm}^{2}$ were used in a Minitan S unit (Millipore, Inc.). The membrane $(15 \mathrm{~cm} \mathrm{x} 8 \mathrm{~cm}$ ) was placed between two acrylic manifolds of thickness $2.3 \mathrm{~cm}$, which were in turn held in place by stainless steel plates of $1.1 \mathrm{~cm}$ thickness.

In a standard Minitan membrane unit, a silicone separator of approximately $1 \mathrm{~mm}$ thickness is used on the feed side of the membrane to create 9 linear flow channels each of approximately $7 \mathrm{~mm}$ width. However, in commercial spiral wound membrane units, a mesh-like feed spacer or turbulence promoter defines the fluid path and promotes greater fluid turbulence at low cross flow velocities. In turn, this reduces concentration polarization and membrane fouling. In order to compare the relative effects of spacers and ultrasound, parallel experiments were conducted using both the standard Minitan silicone separator and a commercial membrane spacer. The commercial spacer was a 50 -mil (1.3 mm) thick polypropylene diamond design from Koch membrane systems. A standard silicone separator was used in all experiments on the permeate side.

A gear pump, operating at 300 to $1000 \mathrm{ml} / \mathrm{min}$ was used to pump the feed solution through the cross flow ultrafiltration unit. This results in crossflow velocities of 0.1 to $0.33 \mathrm{~m} / \mathrm{s}$. The permeate mass was 
measured by an electronic balance connected to a PC. During the experiments the retentate was recycled to the feed tank. An ultrasonic bath (Ultrasonics, Australia, Model FXP14DH) of size (29.5 $\mathrm{cm} \times 24 \mathrm{~cm} \times 20 \mathrm{~cm}$ ) with a frequency of $50 \mathrm{kHz}$ and a nominal power of $300 \mathrm{~W}$ was employed in this study. The membrane unit was completely immersed in $5000 \mathrm{ml}$ of water contained in the ultrasonic bath and kept $3 \mathrm{~cm}$ above the bottom of the ultrasonic bath throughout the entire experimental period. The bath water was replaced as necessary to maintain the temperature in the range, $22-25{ }^{\circ} \mathrm{C}$.

Whey solutions were used as the foulant in all experiments. These solutions were reconstituted from spray dried non-hygroscopic whey powder (Bonlac Australia) using deionised water at $50{ }^{\circ} \mathrm{C}$ and mixed at this temperature for at least 30 minutes or until completely clear. The solution was then cooled to room temperature. The $\mathrm{pH}$ of the prepared whey solution was 6.3 and the average molecular weight of the whey powder was approximately 24,000 .

Whey protein concentrations were determined using a Waters 2690 High Performance Liquid Chromatograph (HPLC) with a C6 reverse phase column and acid saline/acetonitrile gradient elution [37]. A Philips XL30 FEG Field Emission Scanning Electron Microscope was used to image membrane surfaces.

\section{Experimental procedure}

Initially the pure water permeate flux was measured and this value was used as a reference for the membrane permeability. Subsequently, the membrane was fouled for 4 hours with freshly prepared $6 \% \mathrm{w} / \mathrm{w}$ whey solution under different conditions. The steady state permeate flux was determined by averaging the last 10 recorded values of permeate mass. Milli-Q water/distilled water was then fed through the ultrafiltration unit and the final water flux was measured. Two sets of experiments were conducted for each operating condition in order to compare the effect of ultrasound-assisted filtration 
with conventional filtration. Selected experiments were performed in duplicate and an average experimental error in the steady state flux of $\pm 6 \%$ or $\pm 0.3 \times 10^{-6} \mathrm{~m} / \mathrm{s}$ was determined.

The membrane was cleaned between experiments by circulating $0.1 \mathrm{M}$ sodium hydroxide and $15 \mathrm{mM}$ of sodium dodecyl sulfate for 5 minutes. The membrane was then left to soak in this solution. Milli-Q water/distilled water was fed into the unit to flush out the cleaning solution. A further permeate water flux was recorded and compared to the initial water flux.

\section{$\underline{\text { Ultrasonic power determination }}$}

The power transferred into the bath itself was measured calorimetrically by removing the Minitan unit and observing the temperature change with time $[38,39]$. The average power dissipation in the bath itself was found to be only $105 \mathrm{~W}$ using this approach, or $20 \mathrm{~W} /$ litre. Kobayashi et al. [28], working with an identical Millipore Minitan unit, reported that the ultrasonic power intensity reaching the membrane is further reduced by a factor of approximately 10 by transmission through the acrylic and stainless steel membrane holder. This implies that the power per unit volume for the liquid within the membrane holder itself is only approximately $2 \mathrm{~W} /$ litre.

In order to determine if cavitation was occurring within the experimental unit, two additional tests were conducted. In the first case, a piece of household aluminum foil was placed directly in the bath during a sonication cycle. Vigorous transient cavitation was observed, as evidenced by a large number of holes appearing in the foil. However, when the aluminum foil was placed inside the membrane unit, which in turn was placed in the bath, only three or four small pinholes were observed, indicative of much lower levels of cavitational activity. This result confirms that only a small proportion of the ultrasonic power penetrates the membrane holder. 
A second approach involved the measurement of hydrogen peroxide concentrations in sonicated water. The high intensity transient cavitational collapse of micro-bubbles in an ultrasonic field is known to generate free radicals [40]. In particular, sonication in water can result in hydroxyl radicals that react to form hydrogen peroxide. The $\mathrm{H}_{2} \mathrm{O}_{2}$ yield after sonication can thus be used as an indicator of transient cavitational activity [39]. For this work, a small replica of the Minitan unit was constructed with an internal cavity that could be filled with water. Following sonication for 60 minutes, this water was removed and the $\mathrm{H}_{2} \mathrm{O}_{2}$ yield determined as described elsewhere [40]. Similarly, the ultrasonic bath itself was filled with water, sonicated for 60 minutes and also tested for the presence of hydrogen peroxide. In both cases the peroxide concentration was below the limits of detection. This confirms that the intensity of transient cavitation is low within the present experimental arrangement.

\section{Results and discussion}

\section{$\underline{\text { Effect of cross flow rate (CFR) and feed spacers }}$}

Figure 2 shows that both spacers and ultrasound can improve the permeate flux. The spacer is ineffective at low crossflow rate (CFR) but results in a consistently higher permeate flux when this rate is increased. The spacer efficiency $[1,41]$ under such crossflow rates varied from 1.2 to 1.5 . These values are slightly low when compared to other studies. For instance, Schwinge et al. [1] obtained spacer efficiencies of 1.5 to 2.0 after two hours of fouling with reconstituted whey protein concentrate. This lower efficiency may be attributed to both differences in operating conditions and the type and orientation of the spacer used.

Ultrasound is effective across all crossflow rates. An ultrasonic enhancement factor $E_{u s}$ can be defined in a similar manner to the spacer efficiency [23], 
$E_{u s}=\frac{J_{\text {ultrasound }}}{J_{\text {noultrasound }}}$

where $J_{\text {ultrasound }}$ and $J_{\text {noultrasound }}$ are the average steady state permeate fluxes achieved with and without ultrasound. Using this approach, ultrasonic enhancement factors of 1.4 to 1.7 are obtained.

It is of particular interest that ultrasound is still effective even when hydrodynamic turbulence across the membrane is induced by the use of spacers. Indeed, the ultrasonic enhancement factor actually increases slightly for these experiments. Permeate flux can thus be maximized by utilizing ultrasound in combination with a spacer. The total enhancement factor for both ultrasound and a feed spacer in combination is 1.8 to 2.2 at crossflow rates above $540 \mathrm{ml} / \mathrm{min}$.

\section{$\underline{\text { Effect of transmembrane pressure (TMP) and temperature }}$}

Ultrasound is again equally effective under all transmembrane pressures tested in this work with an average enhancement factor of over 1.5 (Figure 3). This is an interesting result, as acoustic cavitation is known to decrease with an increase in external pressure [42]. Thus, if cavitation was the driving mechanism for the observed flux enhancement, it would be expected that this enhancement would be greatest at low TMPs. In fact, the enhancement factor increases slightly as the TMP increases. This suggests that the ultrasound operates through increasing acoustic streaming and mechanical vibration rather than through bubble cavitation. This is consistent with our power determinations discussed above, which similarly showed little evidence of transient bubble cavitation occurring. It should be noted that while data is presented only in the absence of spacers, the trends were again identical when these were present.

Under the experimental conditions used here, permeate flux decreases with increasing transmembrane pressure. As the TMP increases, the greater compressive forces exerted on the cake layer favor a 
thicker and more densely packed cake layer, which offers greater resistance to the permeate flow [43]. Permeate flux increases slightly with solution temperature (Figure 4) which may be attributed to the decrease of viscosity of the solution. Again, the ultrasonic effect is uniform across a range of temperatures.

\section{$\underline{\text { Model calculations }}$}

The best-fit values of the Ho and Zydney model parameters [34] $\alpha, f^{\prime} R^{\prime}$, and $R_{p o}$ were determined for these experiments by minimizing the sum of the squared residuals between the experimental filtrate flux data and the model calculations. The model calculations are in very good agreement with the experimental data over the entire filtration period for all experiments. At short times, the flux decline is dominated by the pore blockage effect, with the data showing a nearly exponential decay in the flux with time. At long times, the flux decline is dominated by the growth of the cake layer. The best-fit values of $\alpha, f^{\prime} R^{\prime}$, and $R_{p o}$ across a range of process conditions are shown in Figure 5 and Table 1.

The pore blockage parameter $\alpha$ is essentially independent of crossflow rate (Figure 5), transmembrane pressure (Table 1) and temperature (data not shown). Pore blockage is reduced slightly when ultrasound is employed. The value of the pore blockage parameter ranges from 2.5 to $3.4 \mathrm{~m}^{2} / \mathrm{kg}$ in the absence of ultrasound. This is in very good agreement with the estimate of $\alpha=2.9 \pm 2.6 \mathrm{~m}^{2} / \mathrm{kg}$, obtained for bovine serum albumin (BSA) using literature data by Ho and Zydney [34]. In the presence of ultrasound this value falls to 2.1 to $2.5 \mathrm{~m}^{2} / \mathrm{kg}$.

The best fit values of $R_{p o}$ and $f^{\prime} R^{\prime}$ decrease with increasing crossflow rate and with the application of ultrasound. This suggests that increasing crossflow velocities and the use of ultrasound both act to 
reduce the resistance of protein deposits. Conversely, resistance increases with transmembrane pressure. There was no significant effect of temperature.

The following empirical relationship, developed by Almy and Lewis [44], is widely used to relate the specific cake resistance to a cake compressibility coefficient $(s)[34,45,46]$.

$R=\beta(\Delta P)^{s}$

The cake compressibility ( $s$ ) varies between zero in an incompressible layer to a value equal or higher than unity for a highly compressible cake [47]. The constant $\beta$ is related primarily to the size and shape of the particles of the fouling cake.

Our values of $R_{p o}$ and $f^{\prime} R^{\prime}$ are consistent with such a relationship (see Figure 6). For the initial protein deposit $R_{p o}$ the deposit compressibility is between 1.1 and 1.3. This relatively high exponent is in contrast to the work of Ho and Zydney, who obtain a value of zero for their BSA system [34]. Pressure dependence is observed in other studies [48], with a value of 0.21 for humic acid filtration. However, extrapolation of our data back to lower values of TMP indicates that our values are consistent in magnitude, with Ho and Zydney who obtain values of 3.5 to $4.0 \times 10^{11} \mathrm{~m}^{-1}$ at transmembrane pressures of 5 to $55 \mathrm{kPa}$.

Ho and Zydney [34] assume that the fractional amount of protein that contributes to deposit growth, $f^{\text {' }}$ is independent of TMP. Making the same assumption, we obtain values for the cake compressibility of 2.1 for standard ultrafiltration. This value reduces to 1.9 when ultrasound is used. This result suggests that the ultrasound acts by 'loosening' the cake and reducing its compressibility. Our results are again consistent in magnitude with the Ho and Zydney results, although their compressibilities are lower. 


\section{Effect of feed concentration}

Consistent with the work of Ho and Zydney [34], the fouling model parameters discussed above are essentially independent of feed concentration. A single set of parameters can be used to fit experimental flux data over the entire time interval and over the full range of whey concentrations.

Of more interest in this case is to consider concentration polarization via the mass transfer coefficient model discussed earlier. Plots of flux data, $J_{v}$, versus feed concentration, $c_{f}$ obtained in the presence of spacers show a linear relationship (See Figure 7). Using Equation 8, the mass transfer coefficient, $k$, within the concentration polarization layer increases from 9.3 to $15.6 \times 10^{-7} \mathrm{~m} / \mathrm{s}$ when ultrasound is applied. This increase is consistent with other published results [14] [49].

In Figure 7, the intercept on the abscissa of these linear plots gives the values of the gel concentration, $\mathrm{c}_{\mathrm{G}}$, for the two experiments. Consistent with the work of Kokugan [49], this gel concentration is not affected by the use of ultrasound. Our experimental value of $56 \%$ is consistent with the value of 58.5 $\mathrm{wt} \%$ for BSA reported by others $[50,51]$.

\section{Effect of ultrasound on membrane life and on dairy solutions}

We observed no damage to the experimental membranes used in this work following many hours of ultrasonic exposure. This is qualitatively supported by consistent values of the water flux through cleaned membranes over many weeks of experimentation. Field emission scanning electron microscope (FESEM) images of membrane surfaces further support the fact that the membrane was not damaged during sonication (figure not shown). This result is to be expected given the low power levels used in these experiments and the minimal detection of transient bubble cavitation discussed above. 
In an alternate series of experiments, the membrane holder was removed from the bath and a beaker containing $6 \mathrm{wt} \%$ of whey solution was added in its place. This beaker was exposed to ultrasound for up to 4 hours. Analysis of the soluble protein content of the resulting solutions using HPLC showed identical concentration profiles in all samples (data not shown). This is consistent with the findings of other workers [52], [53]. However, Villamiel and de Jong [53] do find some evidence for the denaturation of whey proteins when sonication is performed at temperatures in excess of $60 \mathrm{C}$.

\section{Conclusions}

Experimental results reveal that in the whey ultrafiltration process, ultrasound can significantly enhance the permeate flux, with an enhancement factor of between 1.2 and 1.7 across the full range of our experiments. This ultrasonic enhancement occurs even when spacers are concurrently used. The combined effect of spacers and ultrasound can thus lead to a doubling of permeate flux. The main mechanisms involved in flux enhancement are thought to arise from increased acoustic streaming and mechanical vibration. However, the influence of acoustic cavitation can not be completely excluded. The ultrasonic irradiation acts to reduce the resistance of both the initial protein deposit and the growing cake, reducing the compressibility of these deposits. The mass transfer coefficient within the concentration polarization layer also increases.

The ultrasonic power levels used in these experiments are low, of the order of $2 \mathrm{~W} /$ litre for the liquid within the membrane unit. Such low power levels are significant, because they will impact directly on the economic viability of any large scale application of this technology. The low power levels also imply that damage to the membrane surface itself can be minimized and indeed, no such damage was detected in this work. Larger scale trials of ultrasonic application to membrane modules over a number 
of years of operation are required to confirm that impacts below the level of detection in the present work do not reduce total membrane life. Similarly, while our results show that sonication does not appear to change the protein concentration profile within the feed whey solution, further work is required to determine if there could be more subtle effects on the taste, odour or nutritional value of the final dairy products.

\section{Acknowledgements}

HPLC analysis was completed at Food Science Australia's laboratories in Werribee, Victoria. The assistance provided in completing this analysis by both Olga Glagovskaia and Raymond Mawson is gratefully acknowledged. Similarly, the assistance provided by Simon Crawford in obtaining FESEM images is also acknowledged. This work was supported by the Particulate Fluids Processing Centre, a Special Research Centre of the Australian Research Council and this support is also acknowledged.
Nomenclature
$c_{b} \quad$ bulk protein concentration $\left(\mathrm{kg} \mathrm{m}^{-3}\right)$
$c_{G} \quad$ concentration within the gel layer (wt $\left.\%\right)$
$c_{p} \quad$ permeate concentration (wt $\left.\%\right)$
$c_{f} \quad$ bulk feed concentration (wt $\%$ )
CFR Crossflow rate $(\mathrm{ml} / \mathrm{min})$
D diffusivity Coefficient $\left(\mathrm{m}^{2} \mathrm{~s}^{-1}\right)$
$E_{u s} \quad$ ultrasonic enhancement factor 


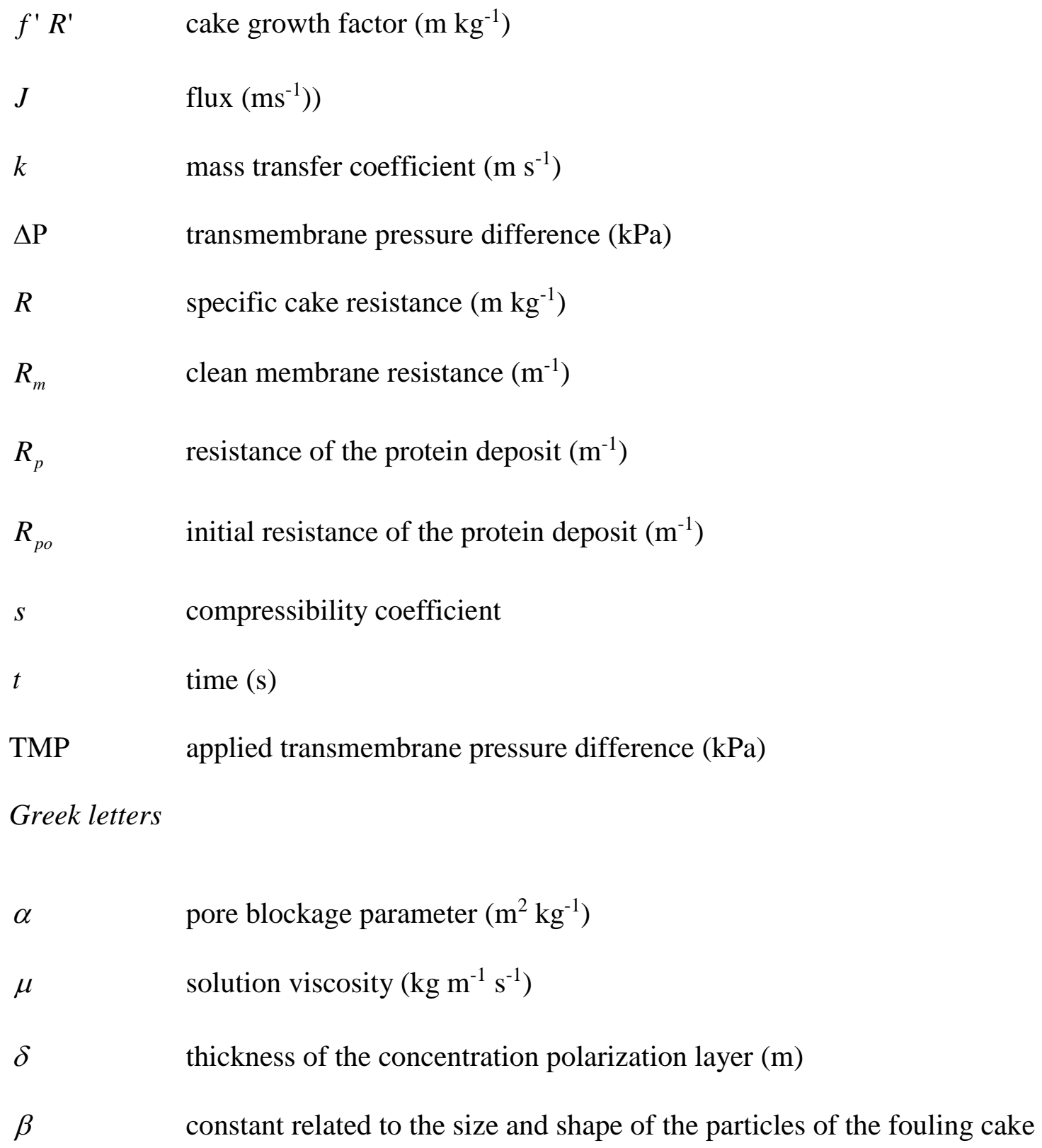

\section{References}

1. J. Schwinge, D.E. Wiley, A.G. Fane, and R. Guenther, Characterization of a zigzag spacer for ultrafiltration, J. Membrane Sci., 172 (1-2) (2000) 19-31.

2. J. Schwinge, D.E. Wiley, and A.G. Fane, Novel spacer design improves observed flux, J. Membrane Sci., 229 (1-2) (2004) 53-61. 
3. S.M. Finnigan and J.A. Howell, The effect of pulsatile flow on ultrafiltration fluxes in a baffled tubular membrane system, Chem. Eng. Res. Des., 67 (3) (1989) 278-82.

4. S. Najarian and B.J. Bellhouse, Effect of liquid pulsation on protein fractionation using ultrafiltration processes, J. Membrane Sci., 114 (2) (1996) 245-253.

5. J. Jurado and B.J. Bellhouse, Application of electric fields and vortex mixing for enhanced ultrafiltration, Filtr. Sep., 31 (3) (1994) 273-81.

6. C. Maranges and C. Fonade, Flux enhancement in crossflow filtration using an unsteady jet, J. Membrane Sci., 123 (1) (1997) 1-8.

7. Q.Y. Li, R. Ghosh, S.R. Bellara, Z.F. Cui, and D.S. Pepper, Enhancement of ultrafiltration by gas sparging with flat sheet membrane modules, Sep. Purifi Technol., 14 (1-3) (1998) 79-83.

8. M. Mercier, C. Fonade, and C. Lafforgue-Delorme, How slug flow can enhance the ultrafiltration flux in mineral tubular membranes, J. Membrane Sci., 128 (1) (1997) 103-113.

9. Z.F. Cui and K.I.T. Wright, Gas-liquid two-phase cross-flow ultrafiltration of BSA and dextran solutions, J. Membrane Sci., 90 (1-2) (1994) 183-9.

10. E.S. Tarleton and R.J. Wakeman, Electro-acoustic crossflow microfiltration, Filtr. Sep., 29 (5) (1992) $425-32$.

11. E.S. Tarleton, How electric and ultrasonic fields assist membrane filtration, Filtr. Sep., 25 (6) (1988) $402-6$.

12. H.S. Muralidhara, N. Senapati, D. Ensminger, and S.P. Chauhan, Electro-acoustic separation process for fine particle suspension, Filtr. Sep., 23 (6) (1986) 351-3.

13. T.J. Mason, L. Paniwnyk, and J.P. Lorimer, The uses of ultrasound in food technology, Ultrason. Sonochem., 3 (3) (1996) S253-S260.

14. T. Kobayashi, X. Chai, and N. Fujii, Ultrasound enhanced cross-flow membrane filtration, Sep. Purif. Technol., 17 (1) (1999) 31-40.

15. I. Masselin, X. Chasseray, L. Durand-Bourlier, J.M. Laine, P.Y. Syzaret, and D. Lemordant, Effect of sonication on polymeric membranes, J. Membrane Sci., 181 (2) (2001) 213-220.

16. T. Kobayashi, T. Kobayashi, and N. Fujii, Effect of ultrasound on enhanced permeability during membrane water treatment, Jap. J. Appl. Phys. Part 1: Regular Papers, Short Notes \& Review Papers, 39 (5B) (2000) $2980-2981$.

17. H. Duriyabunleng, J. Petmunee, and C. Muangnapoh, Effects of the ultrasonic waves on microfiltration in plate and frame module, J. Chem. Eng. Jpn., 34 (8) (2001) 985-989. 
18. J. Li, R.D. Sanderson, and E.P. Jacobs, Ultrasonic cleaning of nylon microfiltration membranes fouled by Kraft paper mill effluent, J. Membrane Sci., 205 (1-2) (2002) 247-257.

19. X. Chai, T. Kobayashi, and N. Fujii, Ultrasound-associated cleaning of polymeric membranes for water treatment, Sep. Purif. Technol., 15 (2) (1999) 139-146.

20. Y. Matsumoto, T. Miwa, S. Nakao, and S. Kimura, Improvement of membrane permeation performance by ultrasonic microfiltration, J. Chem. Eng. Jpn., 29 (4) (1996) 561-567.

21. X. Chai, T. Kobayashi, and N. Fujii, Ultrasound effect on cross-flow filtration of polyacrylonitrile ultrafiltration membranes, J. Membrane Sci., 148 (1) (1998) 129-135.

22. J. Kost and R.S. Langer, Ultrasound enhancement of membrane permeability, US, 4780212, 1988.

23. A. Simon, N. Gondrexon, S. Taha, J. Cabon, and G. Dorange, Low-frequency ultrasound to improve dead-end ultrafiltration performance, Sep. Sci. Technol., 35 (16) (2000) 2619-2637.

24. A. Simon, L. Penpenic, N. Gondrexon, S. Taha, and G. Dorange, A comparative study between classical stirred and ultrasonically-assisted dead-end ultrafiltration, Ultrason. Sonochem., 7 (4) (2000) 183-186.

25. D. Chen, L.K. Weavers, and H.W. Walker, Using ultrasound to reduce ceramic membrane fouling by silica particles, Preprints of Extended Abstracts presented at the ACS National Meeting, American Chemical Society, Division of Environmental Chemistry, 42 (1) (2002) 166-169.

26. N. Ahner, D. Gottschlich, S. Narang, D. Roberts, S. Sharma, and S. Ventura, Piezoelectrically assisted ultrafiltration, Sep. Sci. Technol., 28 (1-3) (1993) 895-908.

27. K.S. Suslick, Ultrasound; Its chemical physical and biological effects, VCH Publisher, new York, 1988.

28. T. Kobayashi, T. Kobayashi, Y. Hosaka, and N. Fujii, Ultrasound-enhanced membrane-cleaning processes applied water treatments: influence of sonic frequency on filtration treatments, Ultrasonics, 41 (3) (2003) 185-190.

29. M.O. Lamminen, H.W. Walker, and L.K. Weavers, Mechanisms and factors influencing the ultrasonic cleaning of particle-fouled ceramic membranes, J. Membrane Sci., 237 (1-2) (2004) 213-223.

30. S. Muthukumaran S. Kentish, S. Lalchandani, M. Ashokkumar, R. Mawson, G.W. Stevens, F. Grieser, The Optimisation of Ultrasonic Cleaning Procedures for Dairy Fouled Ultrafiltration Membranes Ultrason. Sonochem. 12(1-2) (2005) 29-35

31. S. Muthukumaran, K. Yang, A. Seuren, M. Ashokkumar, S. Kentish, G. Stevens, F. Grieser, The Use of Ultrasonic Cleaning for Ultrafiltration Membranes in the Dairy Industry, Sep. \& Purificat. Technol., (2004) 3999 - 
32. C. Zhu and G. Liu, Modeling of ultrasonic enhancement on membrane distillation, J. Membrane Sci.,176 (1) (2000) 31-41.

33. G. Jonsson, Boundary layer phenomena during ultrafiltration of dextran and whey protein solutions, Desalination, 51 (1) (1984) 61-77.

34. C.-C. Ho and A.L. Zydney, A Combined Pore Blockage and Cake Filtration Model for Protein Fouling during Microfiltration, J. Colloid Interface Sci., 232 (2) (2000) 389-399.

35. M. Davey, K. Landman, J.M. Perera, G.W. Stevens, N.D. Lawrence, and M. Iyer, Measurement and prediction of the ultrafiltration of whey protein, AIChE J., 50 (7) (2004) 1431-1437.

36. M. Cheryan, Ultrafiltration Handbook, Technomic Publishing Company, Inc, USA, 1986.

37. R.J. Pearce, Analysis of whey proteins by high performance liquid chromatography, Aust. J. Dairy Technol., 38 (3) (1983) 114-17.

38. T. Kimura, T. Sakamoto, J.-M. Leveque, H. Sohmiya, M. Fujita, S. Ikeda, and T. Ando, Standardization of ultrasonic power for sonochemical reaction, Ultrason. Sonochem., 3 (3) (1996) S157-S161.

39. Ratoarinoro, F. Contamine, A.M. Wilhelm, J. Berlan, and H. Delmas, Power measurement in sonochemistry, Ultrason. Sonochem., 2 (1) (1995) S43-S47.

40. A.E. Alegria, Y. Lion, T. Kondo, and P. Riesz, Sonolysis of aqueous surfactant solutions: probing the interfacial region of cavitation bubbles by spin trapping, J. Phys. Chem., 93 (12) (1989) 4908-13.

41. A.R. Da Costa, A.G. Fane, and D.E. Wiley, Ultrafiltration of whey protein solutions in spacer-filled flat channels, J. Membrane Sci., 76 (2-3) (1993) 245-54.

42. T.G. Leighton, The acoustic bubble, Academic Press, San Diego, 1994.

43. A.-S. Jonsson and B. Jonsson, Ultrafiltration of colloidal dispersions-a theoretical model of the concentration polarization phenomena, J. Colloid Interface Sci., 180 (2) (1996) 504-518.

44. C. Almy, Jr. and W.K. Lewis, Factors Determining the Capacity of a Filter Press, J. Indus. Eng. Chem. (Washington, D. C.), 4 (1912) 528.

45. M.C. Porter, What, when, and why of membranes MF, UF, and RO, AIChE Symposium Series, 73 (171) (1977) 83-103. 
46. P.A. Belter, E.L. Cussler, and W.S. Hu, Bioseparations- Downstream Processing for Biotechnology, Wiley, New York, 1988.

47. W.S.W. Ho and K.K. Sirkar, Membrane Handbook, Van Nostrand Reinhold, New York, 1992.

48. W. Yuan, A. Kocic, and A.L. Zydney, Analysis of humic acid fouling during microfiltration using a pore blockagecake filtration model, J. Membrane Sci., 198 (1) (2002) 51-62.

49. T. Kokugan, Kaseno, S. Fujiwara, and M. Shimizu, Ultrasonic effect on ultrafiltration properties of ceramic membrane, Membrane, 20 (3) (1995) 213-23.

50. V.L. Vilker, C.K. Colton, and K.A. Smith, Concentration polarization in protein ultrafiltration. Part II: Theoretical and experimental study of albumin ultrafiltered in an unstirred cell, AIChE J., 27 (4) (1981) 637-45.

51. A.A. Kozinski and E.N. Lightfoot, Protein ultrafiltration. General example of boundary layer filtration, AIChE J., 18 (5) (1972) 1030-40.

52. D.M. Wrigley and N.G. Llorca, Decrease of Salmonella typhimurium in skim milk and egg by heat and ultrasonic wave treatment, J. Food Prot., 55 (1992) 678-680.

53. M. Villamiel and P. De Jong, Influence of high-intensity ultrasound and heat treatment in continuous flow on fat, proteins, and native enzymes of milk. [Erratum to document cited in CA132:236139], J. Agric. Food Chem., 48 (7) (2000) 3068. 


\section{$\underline{\text { Table Captions }}$}

Table 1. The best-fit values of the model parameters in the presence of spacers at variable TMP and a crossflow rate of $540 \mathrm{ml} / \mathrm{min}$. 


\section{$\underline{\text { Figure Captions }}$}

Figure 1 Experimental set-up for ultrasound-assisted use of polymeric membranes in a cross-flow unit (PG represents the pressure gauge).

Figure 2. Final permeate flux of $6 \%$ whey solution after 4 hours of an experimental run at a constant TMP of $300 \mathrm{kPa}$ and variable crossflow rate.

Figure 3. Permeate flux of $6 \%$ whey solution after 4 hours of an experimental run at variable TMP and at constant crossflow rate of $540 \mathrm{ml} / \mathrm{min}$ in the absence of spacers.

Figure 4. Permeate flux of $6 \%$ whey solution after 4 hours of an experimental run at a constant TMP of $300 \mathrm{kPa}$ and crossflow rate of $710 \mathrm{ml} / \mathrm{min}$ with spacers and at variable temperature.

Figure 5. Best fit values of the fouling parameters as a function of the crossflow rate at a constant TMP of $300 \mathrm{kPa}$ in the presence of spacers.

Figure 6. Initial protein layer resistance, $\boldsymbol{R}_{\boldsymbol{p}}$ (top) and specific protein layer resistance $\boldsymbol{f}^{\prime} \boldsymbol{R}^{\prime}$ (bottom) as a function of transmembrane pressure. The solid line represents results from linear regression based on Equation (10).

Figure 7. The relationship between permeation flux and feed concentration for whey solutions after 4 hours of filtration at constant TMP of $300 \mathrm{kPa}$, crossflow rate of $540 \mathrm{ml} / \mathrm{min}$ with spacers. 
Table 1

\begin{tabular}{|c|c|c|c|c|c|c|}
\hline \multirow{2}{*}{$\begin{array}{c}\text { TMP } \\
(\mathrm{kPa})\end{array}$} & \multicolumn{5}{|c|}{ Parameters } \\
\hline & \multicolumn{2}{|c|}{$\alpha\left(\mathrm{m}^{2} / \mathrm{kg}\right)$} & \multicolumn{2}{|c|}{$R_{p o}\left(\times 10^{13} \mathrm{~m}^{-1}\right)$} & \multicolumn{2}{c|}{$f^{\prime} R^{\prime}\left(\times 10^{13} \mathrm{~m} / \mathrm{kg}\right)$} \\
\cline { 2 - 7 } & $\mathrm{US}$ & $\mathrm{NO}$ US & US & NO US & US & NO US \\
\hline 55 & $2.1 \pm 0.1$ & $2.8 \pm 0.1$ & $0.37 \pm 0.01$ & $0.65 \pm 0.02$ & $0.04 \pm 0.002$ & $0.13 \pm 0.008$ \\
\hline 150 & $2.2 \pm 0.1$ & $3.1 \pm 0.1$ & $1.25 \pm 0.04$ & $2.17 \pm 0.07$ & $0.18 \pm 0.01$ & $0.53 \pm 0.03$ \\
\hline 225 & $2.3 \pm 0.1$ & $3.4 \pm 0.1$ & $1.97 \pm 0.07$ & $4.4 \pm 0.2$ & $0.38 \pm 0.02$ & $1.66 \pm 0.09$ \\
\hline 300 & $2.4 \pm 0.07$ & $3.1 \pm 0.1$ & $4.88 \pm 0.1$ & $4.76 \pm 0.1$ & $1.18 \pm 0.09$ & $5.62 \pm 0.1$ \\
\hline
\end{tabular}


Figure 1

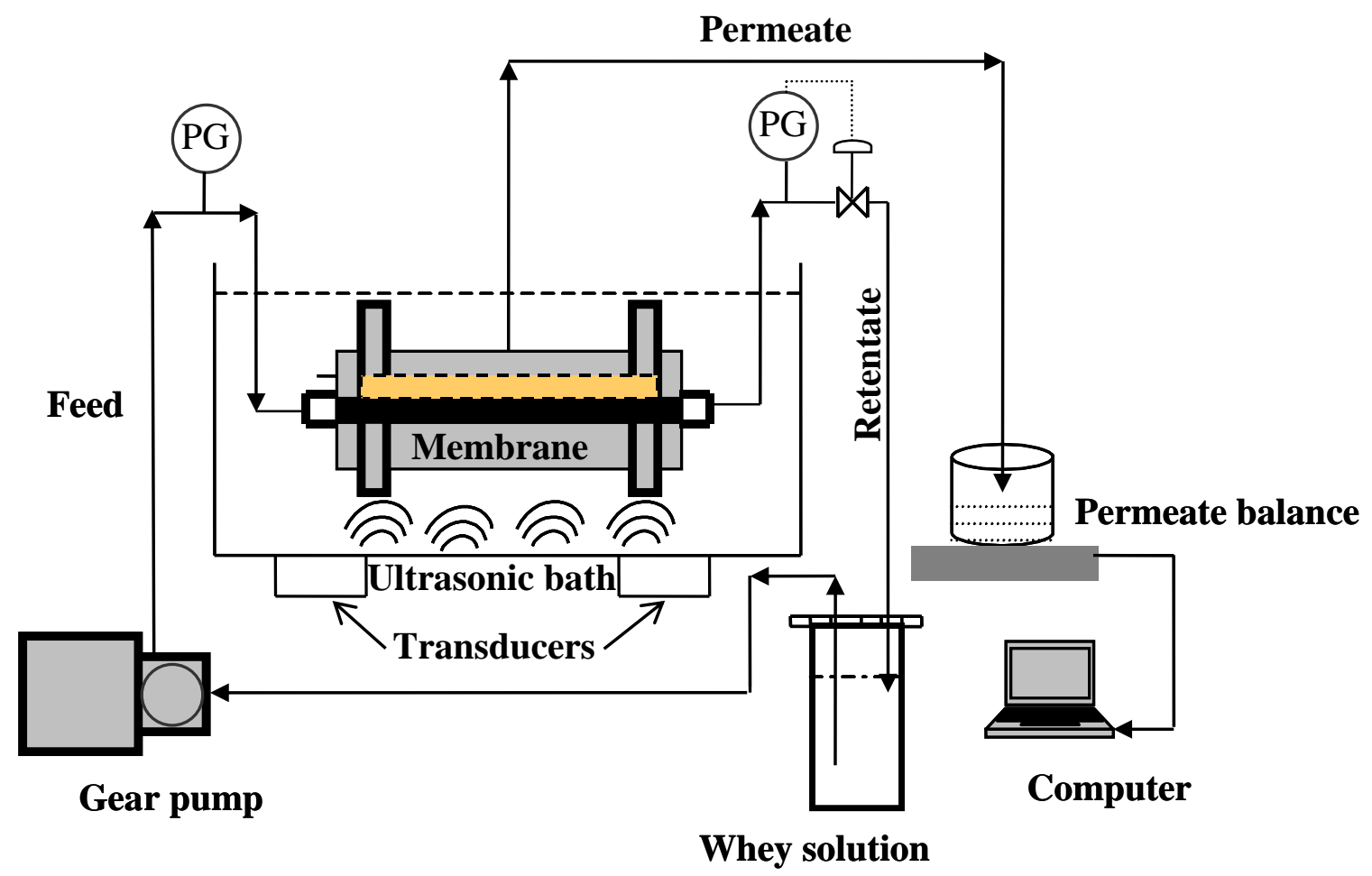


Figure 2

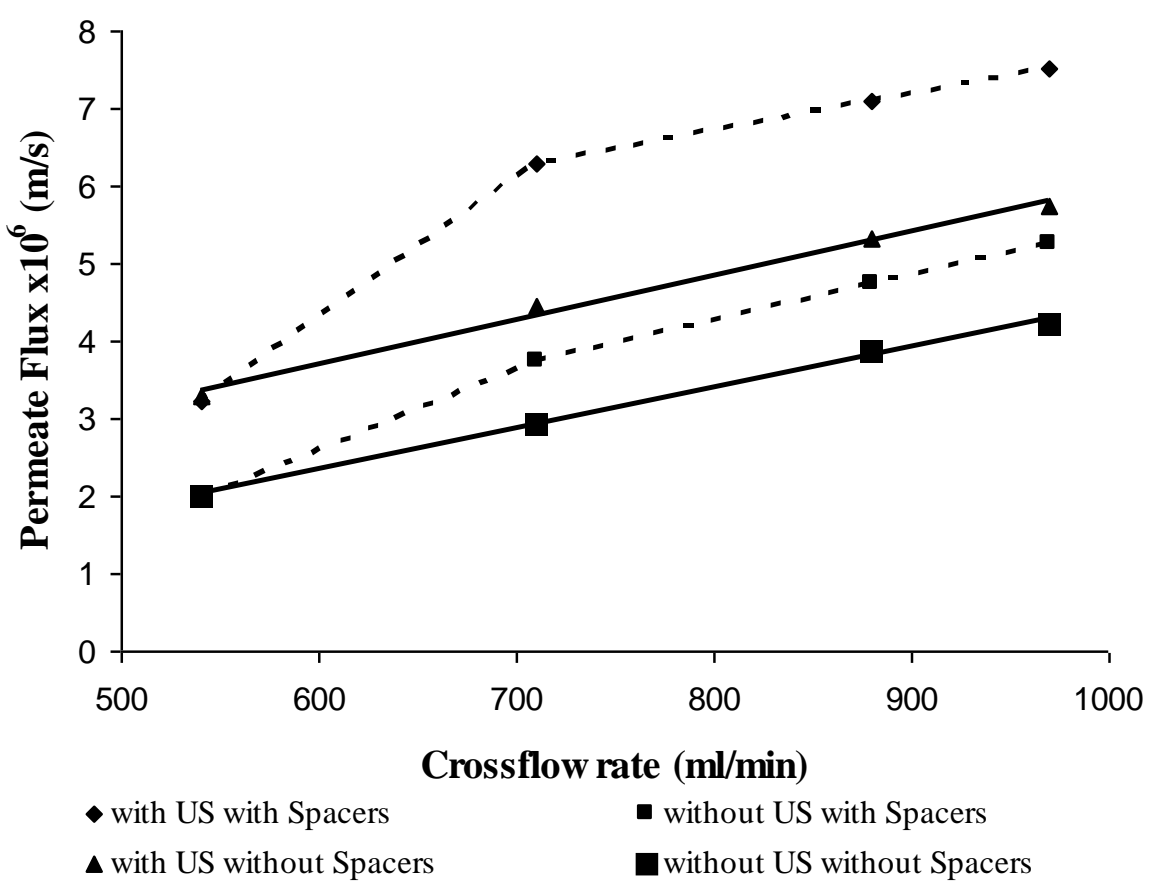


Figure 3

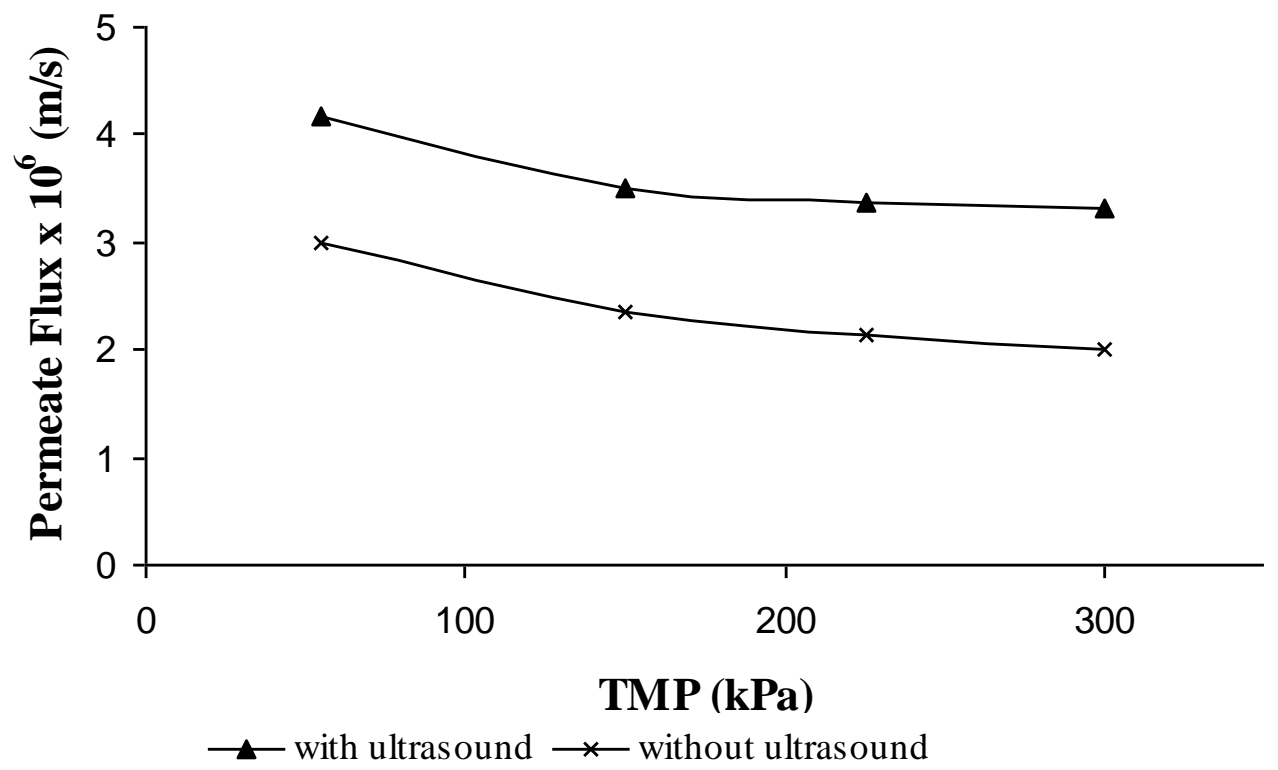


Figure 4

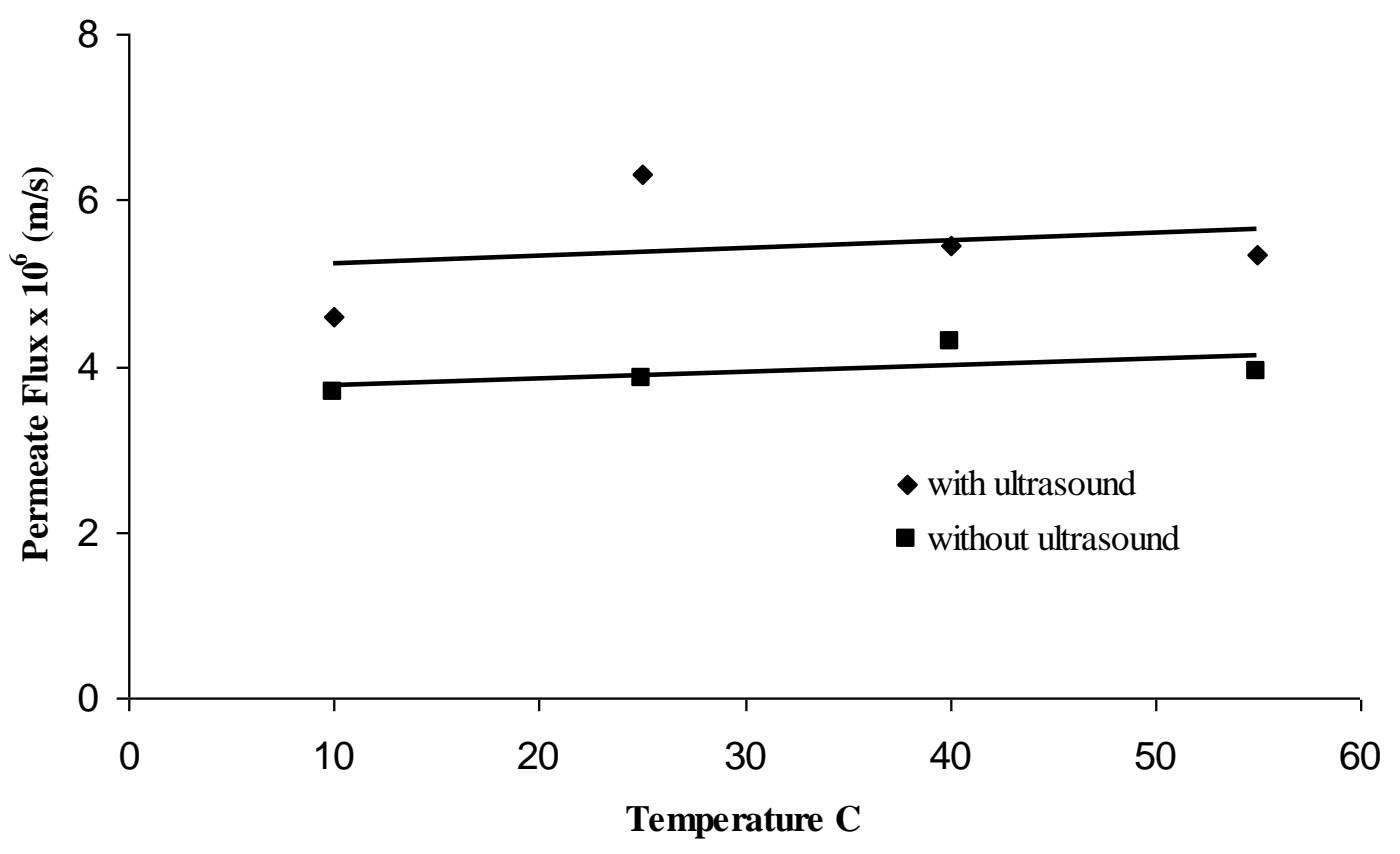


Figure 5
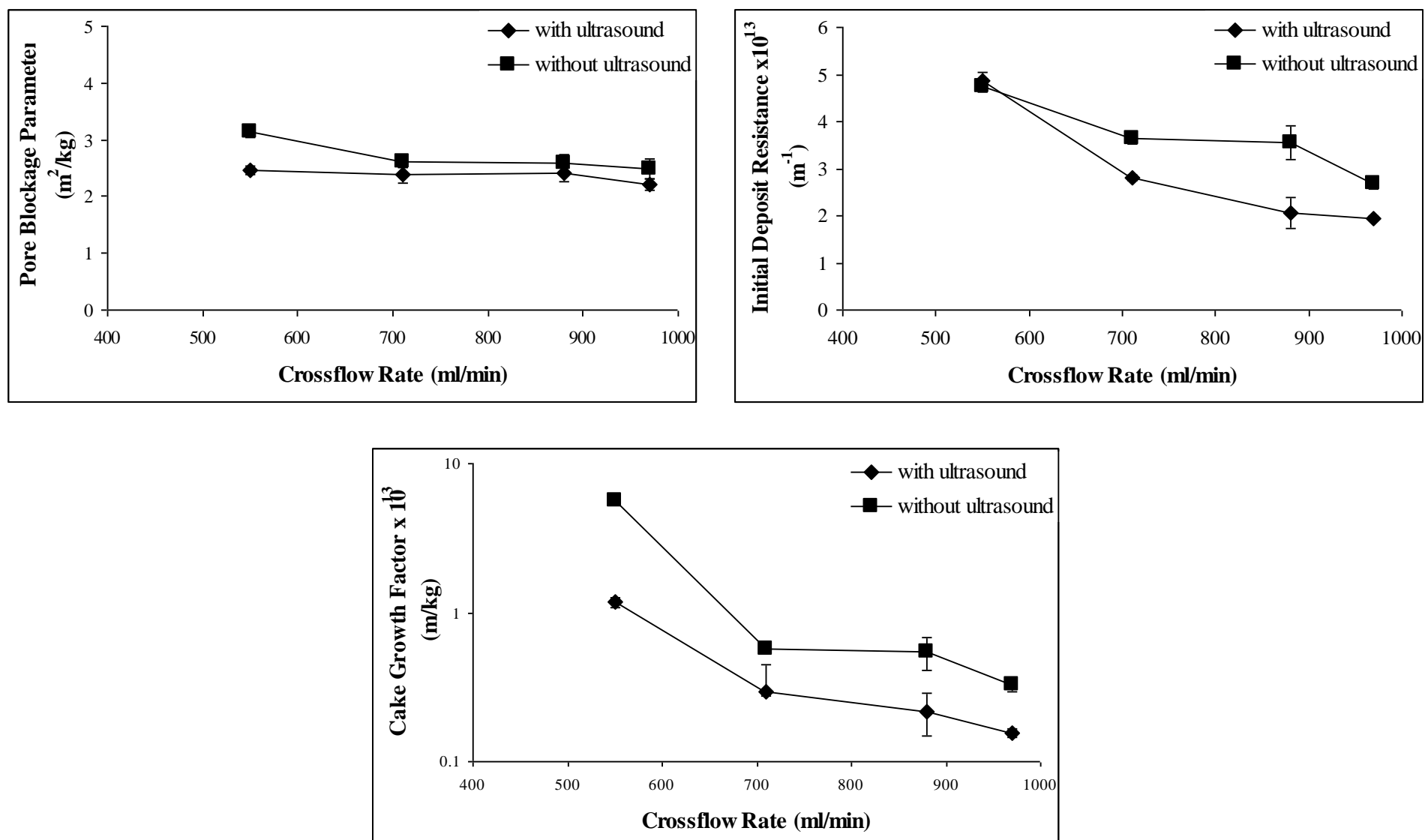
Figure 6
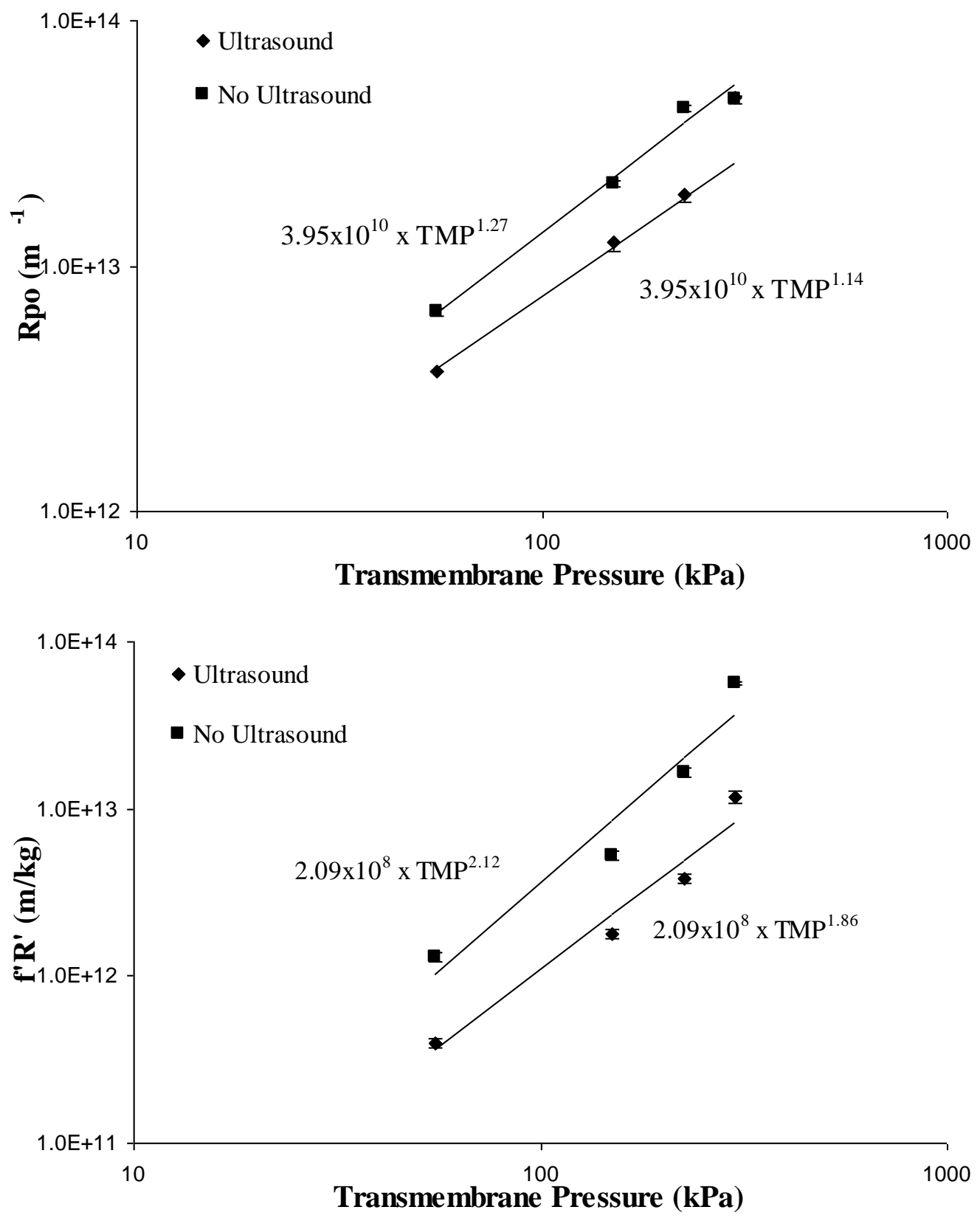
Figure 7

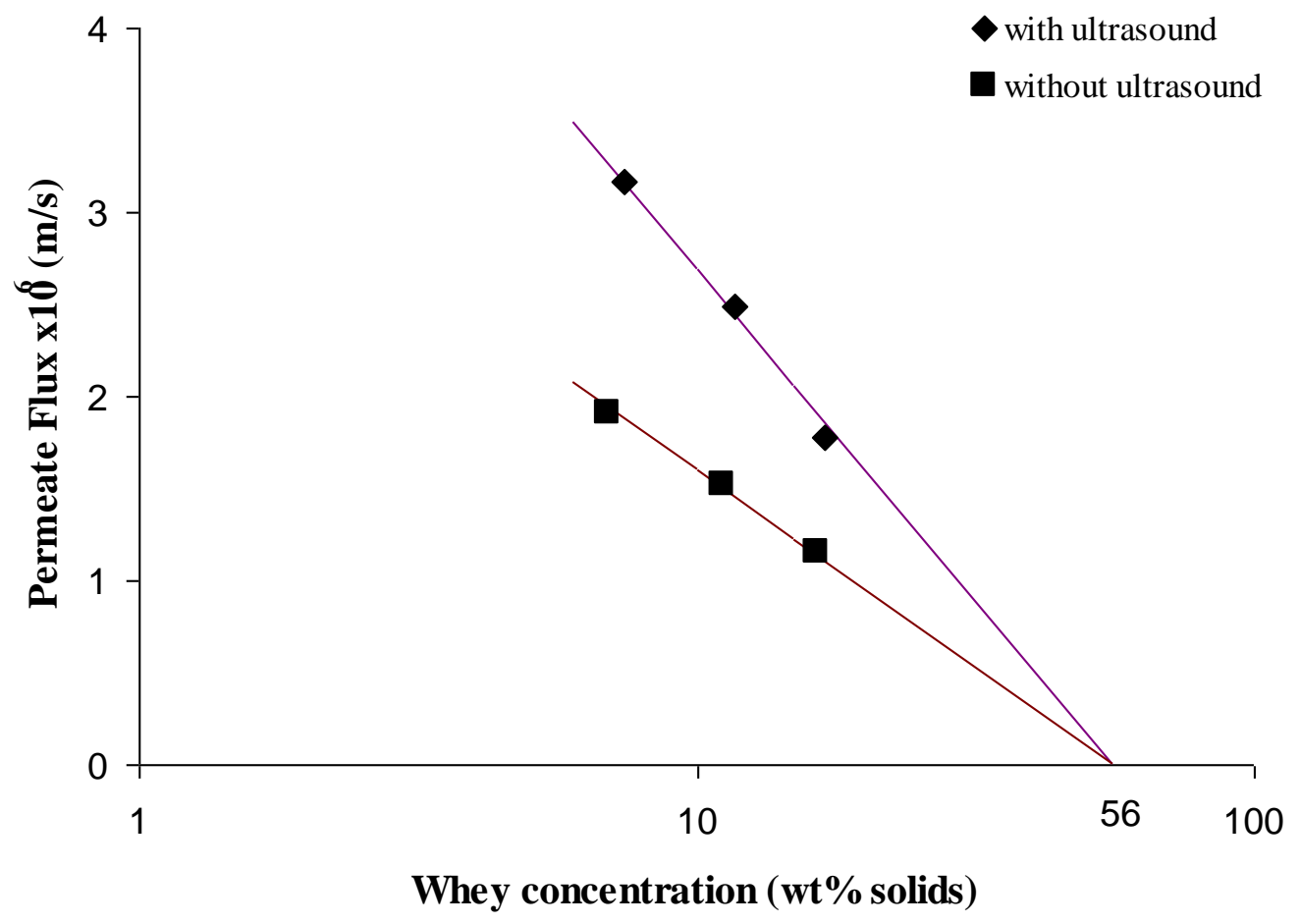

